American Journal of Agricultural and Biological Sciences 2 (4): 248-253, 2007

ISSN 1557-4989

(C) 2007 Science Publications

\title{
New Low-Temperature Technology of Producing Calcium Feed Phosphate with Microelements
}

\author{
Józef Hoffmann \\ Department of Chemistry, Institute of Inorganic Technology and Mineral Fertilizers, \\ Technical University of Wrocław, 50370 Wrocław, \\ wyb. Stanisława Wyspiańskiego 27,Poland
}

\begin{abstract}
The possibility of producing feed calcium phosphates in a way ensuring a low physical water content in the product was investigated in laboratory conditions. For this purpose the process use of a phosphoric acid solution with a higher (than in conventional methods) $\mathrm{P}_{2} \mathrm{O}_{5}$ content (53-63\% by wt. $\mathrm{P}_{2} \mathrm{O}_{5}$ ) with $\mathrm{CaO}$ (molar fraction of $0.5-0.8$ ) and $\mathrm{CaCO}_{3}$ in the phosphoric acid neutralizing mixture was tested. Phosphates with a high content of phosphorous forms highly assimilable by animals, soluble in $0.4 \% \mathrm{HCl}(94-99 \%)$, were obtained. The physical water content of $1-4 \%$ by wt. $\mathrm{H}_{2} \mathrm{O}$ was obtained when a phosphoric acid solution with a $59 \%$ by wt. $\mathrm{P}_{2} \mathrm{O}_{5}$ content and a $\mathrm{CaO}$ molar fraction of 0.8 in the neutralizing mixture were used and for a phosphoric acid solution with a $63 \%$ by wt. $\mathrm{P}_{2} \mathrm{O}_{5}$ content. A temperature above $160^{\circ} \mathrm{C}$ was obtained when respectively phosphoric acid with a $59 \%$ by wt. $\mathrm{P}_{2} \mathrm{O}_{5}$ content and the highest $\mathrm{CaO}$ fraction in the neutralizing mixture and a phosphoric acid solution with a $63 \%$ by wt. $\mathrm{P}_{2} \mathrm{O}_{5}$ content were used. An elevated $\mathrm{CO}_{2}$ content in the products, indicating an increase in the unreacted calcium carbonate content, was found when a phosphoric acid solution containing $59 \%$ by wt. $\mathrm{P}_{2} \mathrm{O}_{5}$ and a $\mathrm{CaO}$ fraction of 0.8 in the neutralizing mixture were used and also for a phosphoric acid solution with a $63 \%$ by wt. $\mathrm{P}_{2} \mathrm{O}_{5}$ content and a $\mathrm{CaO}$ fraction of $0.7-0.8$ in the neutralizing mixture. By supplementing extraction phosphorous acid composition with microelements ( $\mathrm{Se}, \mathrm{Cu}$ and $\mathrm{Zn}$ compounds) at the stage of extraction phosphoric acid production one can obtain a product with a homogenous content of the elements, but this entails losses as high as 70$80 \%$ caused by the separation of phosphogypsum from the phosphorous material decomposition product. Because of the different mass fractions of microelement salts and feed phosphates a homogenous selenium compound content in feed phosphate is obtained only after 8 hours of mixing. Mixing time is twice shorter for copper and zinc.
\end{abstract}

Key words: feed phosphates, calcium phosphates, microelements

\section{INTRODUCTION}

Besides phosphatic fertilizers, feed phosphates are the main product of the phosphorous compounds industry. As a result of the occurrence of CreutzfeldJakob disease (BSE), caused mainly by the use of meatand-bone meal for the production of feedstuffs, the industry's interest in products based on chemical production methods (which despite the unfavourable opinions as to the impact of the manufacture process on the environment have proved to be safer in animal raising) has considerably increased. Also the modifications introduced into feed phosphate production have contributed to the attractiveness of chemical feed phosphate production technologies. The high-temperature processes or the technologies in which calcium phosphates were precipitated through crystallization (requiring filtration and the management of huge quantities of postcrystallization and washing solutions) have been replaced by processes based on the use of concentrated solutions of extraction phosphoric acid (a relatively cheap stock produced for the fertilizer industry), making it possible to simplify the technological process and reduce energy expenditures for the final drying of the phosphates and thus to improve the economic effectiveness of the industrial production of feed phosphates ${ }^{[1-4]}$.

Considering a concept of a new feed phosphate production facility it was deemed necessary to carry out studies of the processes and unit operations involved ${ }^{[5-}$

${ }^{8]}$. Phosphoric acid produced for fertilizer purposes, containing at least $54 \%$ by wt. $\mathrm{P}_{2} \mathrm{O}_{5}$, was to be used for the production of feed phosphates. Because of its impurities, mainly fluorine and heavy metal compounds

Corresponding Author: Józef Hoffmann, Wrocław University of Technology, Department of Chemistry, Institute of Inorganic Technology and Mineral Fertilizers, 50370 Wrocław, Poland, Fax: 0713203469 
$(\mathrm{Pb}, \mathrm{Cd}, \mathrm{As}, \mathrm{Hg})$, this product must be purified to meet the zootechnical requirements for the permissible levels of the elements ${ }^{[9]}$. The current all-European regulations in this field specify the permissible content of fluorine at $0.2 \%$ by wt., $\mathrm{Cd}$ and $\mathrm{As}$ at $10 \mathrm{mg} / \mathrm{kg}, \mathrm{Pb}$ at $15 \mathrm{mg} / \mathrm{kg}$ and $\mathrm{Hg}$ at $0.1 \mathrm{mg} / \mathrm{kg}$. According to the adopted concept, the phosphoric acid solution will be neutralized with a mixture of oxygen and calcium hydroxide or carbonate, whose composition will make it possible to utilize the reaction energy to maximally remove physical water from the system. Thus the thermal conditions of the process should ensure a low water content in the final product, but in view of possible polycondensation reactions of orthophosphates the process temperature should not exceed $160^{\circ} \mathrm{C}$. The elimination of feed phosphate drying after the neutralization of extraction phosphoric acid with calcium compounds has an important bearing on the unit costs of feed phosphate production. Until the end of the 20th century the technological methods of manufacturing feed phosphates were as a rule based on phosphoric acid solutions with a $30 \%$ by wt. $\mathrm{H}_{2} \mathrm{O}$ content. The water was removed in an expensive (usually nonmembrane) drying operation. This production stage was not only costly but also could increase the impurities (including dioxin) content due to the direct contact of the product with the drying gases.

Besides phosphorous and calcium, mineral feeds should also contain other indispensable micronutrient elements such as copper and zinc or ultraelements such as selenium ${ }^{[10,11]}$.

The main problem associated with feed phosphate production from higher concentrated extraction phosphoric acid solutions is the neutralization of phosphoric acid with calcium compounds (calcium oxide, hydroxide or carbonate). At a limited water content in the system the reaction proceeds in conditions characterized by increased viscosity and the presence of a solid phase. In order to achieve the proper conversion of the reagents special reactors homogenizers or mixers (e.g. ribbon mixers) intensively agitating the reacting mixture - are used in the industry.

\section{REAGENTS AND INVESTIGATION METHODS}

Neutralization of concentrated extraction phosphoric acid: The neutralization process in laboratory conditions was investigated on an experimental stand based on a ceramic crucible with a capacity of $0.5 \mathrm{dm}^{3}$ and a high-speed $(1400 \mathrm{rpm})$ laboratory agitator T 25 basic ULTRA-TURRAX made by Labortechnik. Each time 100g of phosphoric acid solution with a $\mathrm{P}_{2} \mathrm{O}_{5}$ content of $53.1,58.7$ and $63.0 \%$ by wt. was neutralized in the experiment. The solution was neutralized by a stoichiometric quantity of a mixture of $\mathrm{CaO}$ with $\mathrm{CaCO}_{3}$, in which the molar ratio of $\mathrm{CaO}$ to $\mathrm{CaCO}_{3}$ was respectively: 0.5:0.5, 0.6:0.4, 0.7:0.3 and $0.8: 0.2$. Because of the different quantities of the calcium reagents the theoretical chemical equation according to which the process proceeded had the form:

$$
\underset{\mathrm{CO}_{2}}{\mathrm{H}_{3} \mathrm{PO}_{4}}+\mathrm{n} \mathrm{CaO}+(1-\mathrm{n}) \mathrm{CaCO}_{3} \rightarrow \underset{\text { (1) }}{\mathrm{CaHPO}_{4}}+\mathrm{H}_{2} \mathrm{O}+
$$

Value $\mathrm{n}$ in equation 1 corresponds to the mole fraction of $\mathrm{CaO}$ in the mixture of the calcium compounds. Reagents made by $\mathrm{POCH}$ in Gliwice, whose purity corresponded to the ones used in analytical chemistry, were used in the experiments. In total, three series of experiments, separately for the particular $\mathrm{P}_{2} \mathrm{O}_{5}$ contents in phosphoric acid, were carried out using four kinds of calcium compounds mixtures for phosphoric acid neutralization in each series. Each experiment lasted 1 hour. After cooling the reaction products were subjected to chemical analysis to determine: the total and soluble phosphorous compound contents in a $0.4 \%$ by wt. $\mathrm{HCl}$ solution and the physical water content. Also the maximum temperature of the reacting mixture was measured. The analytical methods applied to commercial feedstuffs were used in the investigations $^{[12]}$. The physical water content was estimated, using thermal analysis (a Netzch derivatograph STA 409C), for only the water from the physical process, without taking into account the water from the dehydration of calcium hydrogenphosphate hydrates. The same methodology was used to determine the $\mathrm{CO}_{2}$ content in the products on the basis of the identification decomposition reaction of the unreacted calcium carbonate proceeding in a temperature range of $860-900^{\circ} \mathrm{C}$.

Supplementation of the chemical composition of feed
phosphates with selenium compounds: The supplementation of the chemical composition of feed phosphates with selenium compounds was investigated by two methods: (1) by simulating the industrial mixing operation in a laboratory ceramic rotary mixer $(30 \mathrm{rpm})$ with a capacity of $1 \mathrm{dm}^{3}$ and (2) by using the extraction phosphoric acid production process into which a chemical compound of selenium was introduced. A 100 g sample of feed dicalcium phosphate (DCP) produced by Tessenderlo and a precisely weighed out amount of $\mathrm{Na}_{2} \mathrm{SeO}_{4}$ powder, corresponding to the theoretical content of $0.05 \mathrm{mg} \mathrm{Se} / \mathrm{kg}$ feed phosphate, were used in the mixing process. The latter was conducted for 8 hours and the selenium content was analyzed after respectively $1,3,5$ and 8 hours. The selenium content was determined by the diaminobenzidine method exploiting the yellow colour of 3,4diaminophenylpiazzoselenium which forms in an acid medium as a result of the reaction of soluble selenates with 3,3-diaminobenzidine ${ }^{[13]}$. The parameters of industrial extraction phosphoric acid production were simulated in laboratory conditions by conducting the decomposition of phosphoric material (Kola apatite) in a glass reactor with a capacity of $0.8 \mathrm{dm}^{3}$, equipped 
with a mechanical mixer (180 rpm), placed in a thermostat. Phosphoric material decomposition by sulphuric acid was conducted at a temperature of $80 \pm$ $1^{\circ} \mathrm{C}$ at a liquid/solid phase mass ratio (L/S) of 2 and a $27 \%$ by wt. $\mathrm{P}_{2} \mathrm{O}_{5}$ content in the liquid phase. Apatite and the liquid reagents (reagent sulphuric acid and water) were fed in batches every 6 minutes, assuming an excess amount of sulphuric acid (molarly 1.03 relative to apatite) and the theoretical course of the process accordant with the chemical equation:

$\mathrm{Ca}_{5}\left(\mathrm{PO}_{4}\right)_{3} \mathrm{~F}+5 \mathrm{H}_{2} \mathrm{SO}_{4}+\mathrm{H}_{2} \mathrm{O} \rightarrow 5 \mathrm{CaSO}_{4} 2 \mathrm{H}_{2} \mathrm{O}+$ $3 \mathrm{H}_{3} \mathrm{PO}_{4}+\mathrm{HF}$

Decomposition was conducted for 4 hours with $0.01 \mathrm{~g} \mathrm{Se}$ (sodium selenate) per $100 \mathrm{~g}$ of apatite added whereby $0.16 \mathrm{mg} \mathrm{Se} / \mathrm{kg}$ was to be obtained in the phosphoric acid solution. A selenium level corresponding to average animal husbandry needs was adopted. After the phosphoric acid solution was separated from solid phosphogypsum five liquid phase samples were taken and the selenium content was determined.

Investigation of the possibility of introducing copper and zinc compounds into feed phosphates: Since feed mineral mixtures are often supplemented with copper and zinc compounds, investigations into the possibility of introducing the above elements into the composition of feed phosphates were carried out. Two options based on similar assumptions as for selenium compounds were tested. The first option consisted in mixing a dicalcium feed phosphate, supplemented with copper and zinc sulphate, in a ceramic rotary mixer. In order to ensure a permanently stable level of the elements in the mixture once a value close to the expected one was achieved the test was still continued for a few hours so that the total mixing time amounted to 17 hours. After $1,3,5,10,14$ and 17 hours of mixing samples were taken and their copper and zinc contents were determined $^{[14,15]}$. The copper content was determined by the iodometric method - by titrating the free iodine released in the reaction of potassium iodide with $\mathrm{Cu}^{2+}$ ions with sodium hyposulphite, whereas zinc was determined complexometrically, exploiting the formation of stable $\mathrm{Zn}^{2+}$ complexes with the disodium salt of ethylenediaminetetraacetic acid. The adopted copper and zinc contents, i.e. about 13-14 g Zn/kg P and $3-4 \mathrm{~g} \mathrm{Cu} / \mathrm{kg} \mathrm{P}$, followed from the animal husbandry recommendations.

The possibility of introducing copper and zinc compounds at the stage of the industrial production of extraction phosphoric acid was examined in a similar way as for selenium compounds by simulating Kola apatite decomposition with sulphuric acid in laboratory conditions. The same methodology as for selenium compounds was applied, i.e. a 3\% stoichiometric excess of sulphuric acid, a decomposition temperature of $80^{\circ} \mathrm{C}$ and a liquid/solid phase ratio of 2 . In accordance with feeding recommendations, precisely weighed out quantities of copper sulphate and zinc sulphate, whose content after the complete transition to a liquid phase should correspond to a level of $1.592 \mathrm{~g} \mathrm{Zn} / \mathrm{kg}$ and $0.3563 \mathrm{~g} \mathrm{Cu} / \mathrm{kg}$ in the obtained phosphoric acid solution, were introduced into the process.

\section{RESULTS AND DISCUSSION}

Results of laboratory tests of phosphoric acid neutralization with calcium compounds: The chemical composition of the obtained feed phosphate samples and the evaluated laboratory test parameters are shown in table 1. Regardless of the experiment conditions, a high phosphorous content in the products in comparison with the content of this component in commercial feed phosphates (DCP) was obtained. Furthermore, almost all the phosphorous compounds occurred in forms soluble in a $0.4 \%$ by wt. $\mathrm{HCl}$ solution (94.5-99.8\%), which are considered to be assimilable by animals. The measured neutralization reaction temperature exceeded $160^{\circ} \mathrm{C}$ already for phosphoric acid with a $58.7 \%$ by wt. $\mathrm{P}_{2} \mathrm{O}_{5}$ content, neutralized with a mixture of $\mathrm{CaO}$ and $\mathrm{CaCO}_{3}$ with a molar fraction of $\mathrm{CaO}$ as high as 0.7. High temperature levels occurred for each of the tested experiment versions also when phosphoric acid with a $63 \%$ by wt. $\mathrm{P}_{2} \mathrm{O}_{5}$ was used. The physical water content in the reaction products, relatively high for phosphoric acid containing $53.1 \%$ by wt. $\mathrm{P}_{2} \mathrm{O}_{5}$ and a small fraction of $\mathrm{CaO}$ in the mixture of calcium compounds used for its neutralization, sharply decreased in the case of phosphoric acids with a higher $\mathrm{P}_{2} \mathrm{O}_{5}$ content and a larger fraction of calcium oxide in the neutralizing mixture. The $\mathrm{CO}_{2}$ content in the products, characterizing the reagent conversion, was low in the experiments in which the least concentrated $(<1.4 \%$ by wt.) phosphoric acid solution was used, whereas in the experiments in which the most concentrated phosphoric acid solutions and the highest $\mathrm{CaO} / \mathrm{CaO}_{3}$ ratios were used the $\mathrm{CO}_{2}$ content exceeded $3 \%$ by wt. The physical water content, the process temperature and the $\mathrm{CO}_{2}$ content in the products depending on the phosphoric acid used and on the fraction of $\mathrm{CaO}$ in the neutralizing mixture are illustrated in figs 1,2 and 3. 
Results of feed phosphate chemical composition supplementation with selenium compounds: The selenium content in samples taken during the mixing of feed phosphate with sodium selenate is shown in table 2. Selenium content values close to the expected ones were obtained as late as after 8 hours of mixing. After 1 hour the selenium content values differed by as much as four times between the two taken samples. The studies have shown that the mixing of two components occurring in so much different quantities is not a simple operation and takes much time. Since in feed phosphates a precisely fixed selenium content must be ensured this way of supplementing their composition with selenium is costly and not without risk.

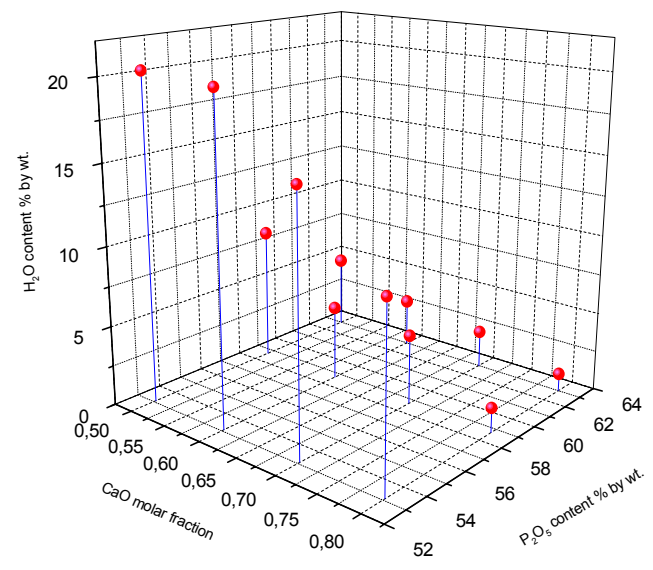

Fig. 1: Physical water content in reaction products depending on $\mathrm{P}_{2} \mathrm{O}_{5}$ content in phosphoric acid solution and $\mathrm{CaO}$ fraction in neutralizing mixture

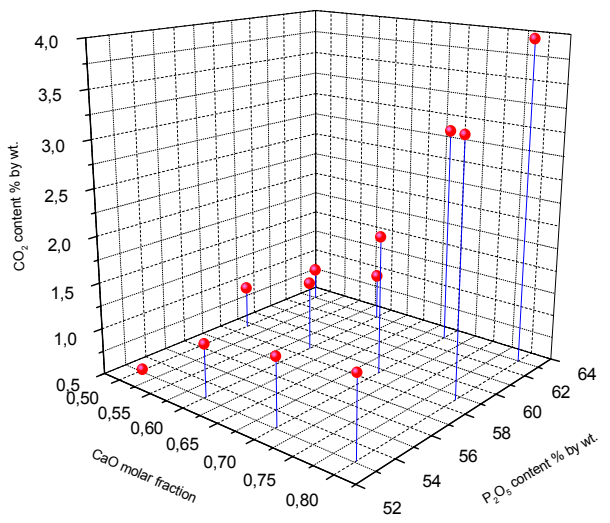

Fig. 2: Temperature of reaction products depending on $\mathrm{P}_{2} \mathrm{O}_{5}$ content in phosphorous acid and $\mathrm{CaO}$ fraction in neutralizing mixture

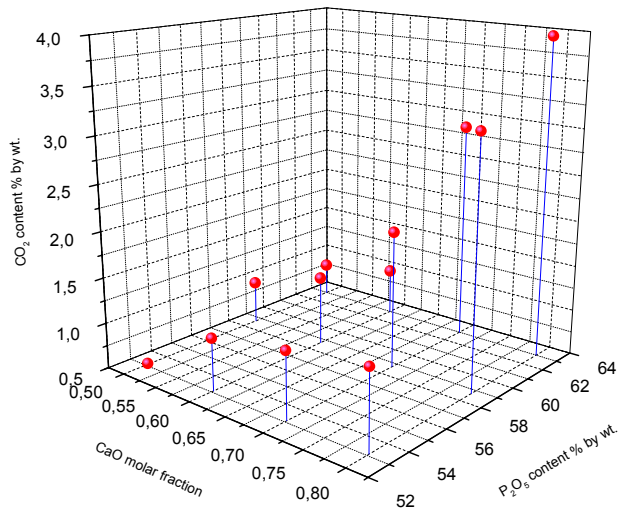

Fig. 3: $\mathrm{CO}_{2}$ content in reaction products depending on $\mathrm{P}_{2} \mathrm{O}_{5}$ content in phosphoric acid solution and $\mathrm{CaO}$ fraction in neutralizing mixture

The selenium content in the phosphorous acid solution produced during the decomposition of apatite with sulphuric acid is shown in table 3. Process specification, temperature and intensive mixing influence the obtained phosphoric acid solution's homogeneity with regard to the selenium content. This way of supplementing the phosphoric acid composition with selenium holds promise that the selenium content will also be homogenous in the produced feed phosphate neutralized with calcium compounds. The drawback is the large loss of selenium compounds caused by the separation of phosphogypsum from the products of decomposition of the phosphorous material (apatite) with sulphuric acid. About $70 \%$ of the selenium introduced into the process involving phosphogypsum was lost. This can be avoided by dissolving sodium selenate in the phosphoric acid solution after phosphogypsum has been separated and, if need be, the selenium has been oxidized to $\mathrm{Se}(\mathrm{VI})$ with a hydrogen peroxide solution.

Results of feed phosphate chemical composition supplementation with copper and zinc compounds: Precisely weighed out quantities of loose feed dicalcium phosphate (DCP) and finely ground reagent copper and zinc sulphates were being mixed. The mixing process was only briefly interrupted at the measuring hours. The copper and zinc contents in the samples taken at the measuring hours were determined. The results are shown in table 4 .

(Table 1 and 2). With UV-B radiation, biomass was increased by $\mathrm{CaCl}_{2} 0.75 \%$, SA and $\mathrm{ASA} 0.100 \%$ in Mianyan 26 and by $\mathrm{CaCl}_{2}$, SA, ASA $0.100 \%$ and DMSO in Huining 18, respectively. 
Am. J. Agril. \& Biol. Sci., 2 (4): 248-253, 2007

Table 1: Results of laboratory tests of phosphoric acid neutralization with mixture of calcium compounds

\begin{tabular}{|c|c|c|c|c|c|c|c|}
\hline No. & $\begin{array}{l}\mathrm{CaO} \text { molar } \\
\text { fraction } \\
\mathrm{n}\end{array}$ & $\begin{array}{c}\mathrm{P}_{2} \mathrm{O}_{5} \\
\text { Content in phosphoric } \\
\text { acid solution } \\
\% \text { by wt. } \mathrm{P}_{2} \mathrm{O}_{5}\end{array}$ & $\begin{array}{l}\text { Total } \\
\text { phosphorous } \\
\% \text { by wt. P }\end{array}$ & $\begin{array}{l}\quad \mathrm{P}_{2} \mathrm{O}_{5} \\
\text { soluble in } \\
0.4 \% \mathrm{HCl} \\
\% \text { by wt. } \mathrm{P}\end{array}$ & $\begin{array}{c}\mathrm{H}_{2} \mathrm{O} \\
\text { \% by wt. }\end{array}$ & $\begin{array}{c}\text { Temperature } \\
{ }^{\circ} \mathrm{C}\end{array}$ & $\begin{array}{c}\mathrm{CO}_{2} \\
\text { \% by wt. }\end{array}$ \\
\hline 1. & 0.5 & 53.1 & 19.98 & 19.72 & 20.27 & 141 & 0.51 \\
\hline 2. & 0.6 & 53.1 & 20.52 & 20.45 & 20.01 & 143 & 1.07 \\
\hline 3. & 0.7 & 53.1 & 20.93 & 20.29 & 15.67 & 145 & 1.22 \\
\hline 4. & 0.8 & 53.1 & 19.82 & 19.75 & 11.02 & 149 & 1.35 \\
\hline 5. & 0.5 & 58.7 & 19.97 & 19.69 & 8.40 & 154 & 0.95 \\
\hline 6. & 0.6 & 58.7 & 20.22 & 20.17 & 4.68 & 158 & 1.26 \\
\hline 7. & 0.7 & 58.7 & 20.47 & 20.37 & 4.38 & 160 & 1.99 \\
\hline 8. & 0.8 & 58.7 & 20.81 & 19.66 & 1.53 & 165 & 3.19 \\
\hline 9. & 0.5 & 63.0 & 20.50 & 20.46 & 4.65 & 161 & 0.86 \\
\hline 10. & 0.6 & 63.0 & 20.89 & 20.53 & 3.01 & 166 & 1.01 \\
\hline 11. & 0.7 & 63.0 & 20.77 & 20.71 & 2.36 & 172 & 2.89 \\
\hline 12. & 0.8 & 63.0 & 19.45 & 19.35 & 1.12 & 177 & 3.96 \\
\hline
\end{tabular}

Table 2: Analysis of selenium content in samples taken while mixing sodium selenate with feed dicalcium phosphate

\begin{tabular}{ccc}
\hline $\begin{array}{c}\text { Mixing time } \\
\text { hours }\end{array}$ & $\begin{array}{c}\text { Sample 1 } \\
\mathrm{mg} \mathrm{Se} / \mathrm{kg}\end{array}$ & $\begin{array}{c}\text { Sample 2 } \\
\mathrm{mg} \mathrm{Se} / \mathrm{kg}\end{array}$ \\
\hline 1 & 0.098 & 0.023 \\
\hline 3 & 0.036 & 0.079 \\
5 & 0.063 & 0.039 \\
8 & 0.049 & 0.046 \\
Expected content & 0.05 & 0.05 \\
\hline
\end{tabular}

Table 3: Selenium content in phosphoric acid solution in laboratory tests

\begin{tabular}{cc} 
No. & $\begin{array}{c}\text { Selenium content } \\
\mathrm{mg} \mathrm{Se} / \mathrm{kg}\end{array}$ \\
\hline 1. & 0.0475 \\
2. & 0.0482 \\
3. & 0.0478 \\
4. & 0.0482 \\
5. & 0.0479 \\
Average content & 0.0479 \\
Expected value & 0.160 \\
\hline
\end{tabular}

Table 4: Analysis of copper and zinc content in samples taken during mixing of copper and zinc sulphate with feed dicalcium phosphate

\begin{tabular}{ccc}
$\begin{array}{c}\text { Mixing time } \\
\text { hours }\end{array}$ & $\begin{array}{c}\text { Zinc content } \\
\mathrm{mg} \mathrm{Zn} / \mathrm{kg}\end{array}$ & $\begin{array}{c}\text { Copper content } \\
\mathrm{mg} \mathrm{Cu} / \mathrm{kg}\end{array}$ \\
\hline 1 & 2211 & 550.7 \\
3 & 2710 & 731.1 \\
5 & 2885 & 770.2 \\
7 & 2856 & 749.4 \\
10 & 2789 & 701.1 \\
14 & 2828 & 769.3 \\
17 & 2810 & 760.5 \\
Expected value & 2808 & 761.3 \\
\hline
\end{tabular}

A copper and zinc content level close to the expected value was reached already after 3-5 hours of mixing. But at the next measuring hours deviations from the expected value were recorded. After 10 hours of mixing the copper content was lower by $7.9 \%$ and the zinc content at the 5 th hour of mixing was by $2.7 \%$ higher. Considering that the requirements as to permissible deviations from the target composition are less stringent, it can be assumed that in the case of the two elements the required mixing time will be significantly shorter than for the corresponding process of enriching feed phosphates with selenium compounds.

Table 5 shows laboratory test results for introducing copper and zinc compounds in a process simulating the production of extraction phosphoric acid. After 4 hours of the decomposition of the phosphorous material with sulphuric acid the reaction products were separated into a phosphoric acid solution and solid phosphogypsum. The copper and zinc content in the liquid phase was analyzed (5 liquid phase samples were taken for analysis).

\begin{tabular}{ccc} 
Table 5: & \multicolumn{3}{c}{$\begin{array}{l}\text { Copper and zinc content in extraction phosphoric acid obtained in } \\
\text { laboratory test }\end{array}$} \\
\hline No. & $\begin{array}{c}\text { Zinc content } \\
\mathrm{mg} \mathrm{Zn} / \mathrm{kg}\end{array}$ & $\begin{array}{c}\text { Copper content } \\
\mathrm{mg} \mathrm{Cu} / \mathrm{kg}\end{array}$ \\
\hline 1. & 314.7 & 85.92 \\
2. & 318.5 & 87.32 \\
3. & 321.3 & 85.92 \\
4. & 315.4 & 89.06 \\
5. & 319.6 & 88.01 \\
Average value & 317.8 & 87.32 \\
Expected value & 1593 & 356.3 \\
\hline
\end{tabular}

The results shown in table 5 indicate a high homogeneity of the elements content in the phosphoric acid solution. This holds promise that the feed phosphate obtained using such phosphoric acid will be characterized by a homogenous content of the elements in the product. Unfortunately, conducting the process in this way one should expect high losses in the added microelement salts as they are removed with phosphogypsum. For the laboratory test conditions the losses amounted to over $75 \%$ for the copper compounds and $80 \%$ for the zinc compounds. These products are not as expensive as selenium compounds but for 
environmental reasons such a solution does not seem to be optimal.

\section{CONCLUSIONS}

Conducting the process of feed phosphates production through the neutralization of phosphoric acid solution with a mixture of $\mathrm{CaO}$ and $\mathrm{CaCO}_{3}$, using phosphoric acid with an elevated $\mathrm{P}_{2} \mathrm{O}_{5}$ (53-63\% by wt.) content and a molar fraction of $\mathrm{CaO}$ in the neutralizing mixture in the order of $0.5-0.8$, a product with a relatively high phosphorous content (about 20\% P) and a high content of phosphorous forms assimilable by animals $(94-99 \%$ soluble in $0.4 \% \mathrm{HCl})$ was obtained. Using an elevated $\mathrm{P}_{2} \mathrm{O}_{5}$ content (at least 59\%) in the phosphoric acid solution and a molar fraction of $\mathrm{CaO}$ in the neutralizing mixture above 0.7 a product with a physical water content of $1-4 \%$ by wt. was directly obtained whereby a drying operation in the feed phosphate production technology can be avoided.

The neutralization process temperature exceeds $160^{\circ} \mathrm{C}$ when a phosphoric acid solution with a $\mathrm{P}_{2} \mathrm{O}_{5}$ content higher than $59 \%$ by wt. and a $\mathrm{CaO}$ molar fraction of 0.8 in the neutralizing mixture are used.

An elevated $\mathrm{CO}_{2}$ content ( $>3 \%$ by wt.) in the neutralization products is observed for phosphoric acid solution with a $59 \%$ by wt. $\mathrm{P}_{2} \mathrm{O}_{5}$ content and a $\mathrm{CaO}$ molar fraction of 0.8 and for phosphoric acid solution with a $63 \% \mathrm{P}_{2} \mathrm{O}_{5}$ content and a $\mathrm{CaO}$ molar fraction of 0.7-0.8.

By introducing microelement $(\mathrm{Se}, \mathrm{Zn}, \mathrm{Cu})$ salts at the stage of production of extraction phosphoric acid one can obtain homogeneity of the microelements content in the whole volume of the product but this leads to high $(70-80 \%)$ losses of the salts in the production technology.

In the test conditions (a ceramic rotary mixer) the introduction of microelement $(\mathrm{Se}, \mathrm{Zn}, \mathrm{Cu}$ ) salts through mixing with ready feed phosphate required about 8 hours of mixing to obtain a homogenous selenium content and a twice shorter mixing time for copper and zinc compounds.

\section{ACKNOWLEDGMENTS}

This work was supported by Polish Ministry of Science and Higher Education the National Natural Science Foundation of China (grant No 1 T09B 072 30).

\section{REFERENCES}

1. Sepehri-Nik E., 1987. The manufacture of calcium phosphate. Phosph. a. Potass., 149: 28-30.
2. 1986. Making DCP. Phosph. a. Potass., 201: 3644.

3. Sinden J., 1997. Calcium phosphates: new markets and new processes. Phosph. a. Potass., 211: 33-37.

4. Gurbuz H., Bulutcu A., 1995. Preparation of reasonably pure calcium orthophosphates from wet-process phosphoric acid. Ind. Eng. Res., 34: 1914-1918.

5. Hoffmann J., 2005. Preparation of feed phosphates enriched with microelements and feed additives report for KBN (in Polish), SPR 1/2005, Pol. Wroc., Wrocław.

6. Hoffmann J., Hoffmann K., 20004. Fodder phosphates - directions of development of manufacture methods, Annals of the Polish Chemical Society, vol. 3, 3: 1305-1308.

7. Hoffmann J., Hoffmann K., 2003. Development tendencies in technologies of feed phosphates production, Chemicals in sustainable agriculture, Czech-Polish Trade, Prague, vol. 4: 60-64.

8. Hoffmann J., Hoffmann K., 2004. Production of feed phosphates from concentrated phosphoric acid, New agrochemicals and their safe use for health and environment, Czech-Polish Trade, Prague, vol. 5: 15-20.

9. Feedstuffs. Feed Phosphates. 1997. Polish Standard, PN - R - 64803 (in Polish).

10. Deptuła W., Szenfeld J., 1993. Vitamins and mineral components in cattle feeding (in Polish). Przegląd Hodowlany, 9: 6 -10.

11. Kinal S., Preś J., Korniewicz A., Chrząszcz E., Kistowski T., 1996. A comparison of calcium and phosphorus requirements according to different standards in dry cows. Journal of Animal and Feed Sciences, 5: 11-23.

12. The Ministry of Agriculture and Countryside Development order concerning analytical procedures for determining nutrient and feed additive content in feed materials, premixes and mixtures (in Polish). Dz. U. 03. 66. 614.

13. Hermanowicz W., Dożańska W., Dojlido J., Koziorowski B., 1976. Physicochemical testing of water and sewage (in Polish), Arkady, Warsaw:320-321.

14. Copper Content Determination by the Iodometric Method, $\mathrm{PN}-80 / \mathrm{C}-84081$ (in Polish).

15. Complexometric Methods of Determining Major Constituent Cation Content, PN - 82/C - 04950 (in Polish). 